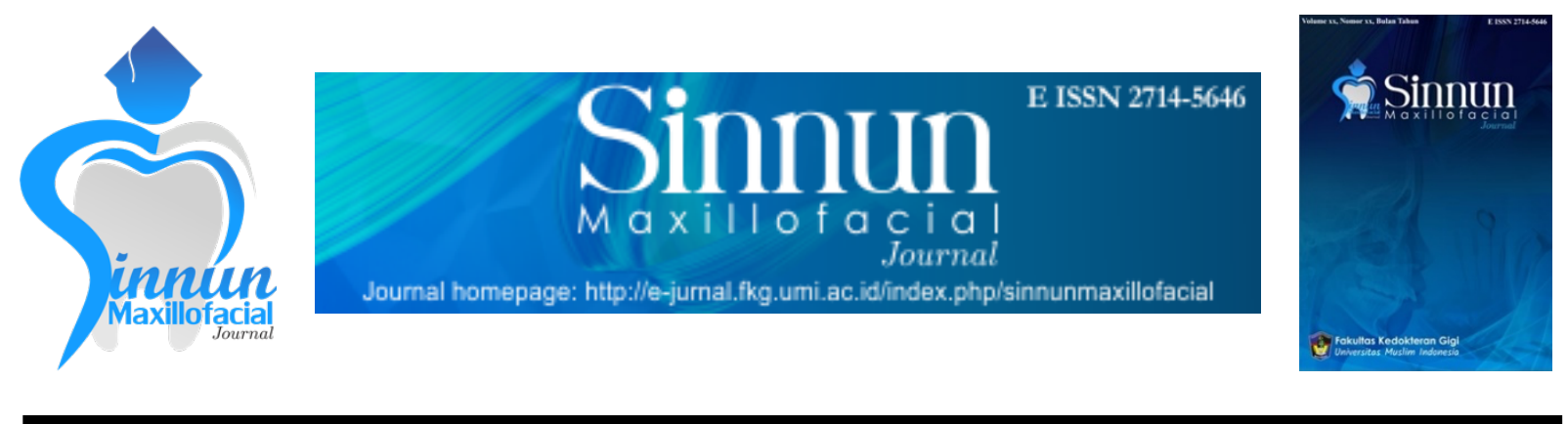

ARTIKEL RISET

URL artikel: http://e-jurnal.fkg.umi.ac.id/index.php/Sinnunmaxillofacial

\title{
Judul Artikel
}

Peningkatan Stabilitas Dimensi Hasil Cetakan Alginat Dengan Penambahan Pati Ubi Kayu dan Pati Sagu

\author{
Syamsiah Syam ${ }^{1}$, Risnayanti Anas ${ }^{2},{ }^{\mathrm{K}} \mathrm{Muhammad} \mathrm{Jayadi} \mathrm{Abdi}^{3}$, Andi Tenri Biba ${ }^{4}$, Chusnul \\ Chotimah $^{5}$, Hendra Purnomo ${ }^{6}$ \\ ${ }^{1,2,3,4,5,6}$ Fakultas Kedokteran Gigi, Universitas Muslim Indonesia \\ Email Penulis Korespondensi $\left({ }^{\mathrm{K}}\right)$ : jayadi.abdi29@gamil.com \\ syams_77@yahoo.com¹, risnayanti.anas@gmail.com², jayadi.abdi29@gmail.com³. \\ anditenribiba2020@gamil.com ${ }^{4}, \underline{\text { chusnulkhotimah70@gmail.com }}{ }^{5}$, phendra46@,rocketmail.com ${ }^{6}$ \\ (082110811001)
}

\begin{abstract}
ABSTRAK
Pendahuluan: Alginat adalah bahan cetakan yang sering digunakan dalam kedokteran gigi. Bahan cetak alginat masih memiliki kelemahan dalam akurasi stabilitas dimensi, dimana alginat memiliki stabilitas dimensi yang cepat berubah. Tujuan Penelitian: Peneltian ini untuk mengetahui pengaruh penambahan pati ubi kayu dan pati sagu terhadap stabilitas dimensi hasil cetakan alginat. Bahan dan Metode: Penelitian ini menggunakan metode True Eksperimental Laboratorium dengan rancangan cross-sectional. Dimana jumlah sampel minimal diestimasikan berdasarkan rumus Federer. Penelitian ini dilakukan di laboratorium terpadu Fakultas Kedokteran Gigi Universitas Muslim Indonesia. Hasil: Telah didapatkan berdasarkan uji one way anova diperoleh p-value sebesar 0,000 $(\mathrm{p}<0,05)$. Berdasarkan uji post hoc multiple comparison diperoleh perbedaan rata-rata antara pati ubi kayu ditambah alginat dengan kelompok kontrol sebesar 0,35500. Sedangkan untuk pati sagu ditambah alginat dengan kelompok kontrol sebesar 0,75500. Kesimpulan: Pada penelitian ini terdapat perubahan yang signifikan antara penambahan pati ubi kayu dan pati sagu terhadap stabilitas dimensi hasil cetakan alginat.
\end{abstract}

Kata kunci: Alginat; pati ubi kayu; pati sagu

\section{PUBLISHED BY:}

Fakultas Kedokteran Gigi

Universitas Muslim Indonesia

\section{Address:}

Jl. Padjonga Dg. Ngalle. 27 Pab’batong (Kampus I UMI)

Makassar, Sulawesi Selatan.

Email: sinnunmaxillofacial.fkgumi@gmail.com 


\section{ABSTRACT}

Introduction: Alginate is a mold material that is often used in dentistry. Alginate printing materials still have weaknesses in the accuracy of dimensional stability, where alginate has dimensional stability that quickly changes. Objectives: This study was to determine the effect of adding cassava starch and sago starch on the dimensional stability of the alginate molding. Materials and Method: This study used the True Experimental Laboratory method with a cross-sectional design. Where the minimum sample size is estimated based on the Federer formula. This research was conducted in the integrated laboratory of the Faculty of Dentistry, Muslim University of Indonesia. Results: It has been obtained based on the one way ANOVA test obtained p-value of $0.000(p<0.05)$. Based on the post hoc multiple comparison test, it was found that the average difference between cassava starch plus alginate and the control group was 0.35500. As for sago starch plus alginate in the control group of 0.75500. Conclusion: In this study, there was a significant change between the addition of cassava starch and sago starch on the dimensional stability of the alginate mold.

Keywords: alginate; cassava starch; sago stare

\section{PENDAHULUAN}

Bahan cetak merupakan suatu bahan yang digunakan untuk mendapatkan reproduksi negatif dari gigi dan jaringan rongga mulut. Hasil cetakan yang diperoleh kemudian dicor dengan gips sehingga diperoleh model kerja atau model studi yang merupakan replika dari gigi dan jaringan rongga mulut. (Febriani, M. 2012). Secara umum bahan cetak diklasifikasikan dalam dua kelompok yaitu bahan cetak elastik dan nonelastik. Bahan cetak yang sering digunakan oleh klinisi adalah bahan cetak elastik terutama irreversible hydrocolloid. Salah satu bahan cetak irreversible hydrocolloid adalah alginate. (Ningsih, DS,. 2016). Alginat merupakan bahan yang sangat populer sebab mudah pencampurannya.Meskipun merupakan bahan cetak yang populer dan banyak dokter gigi yang menggunakan bahan cetak ini, namun masih ada masalah yang berhubungan dengan stabilitas dimensi dan hasil cetakan yang kurang detail sehingga pemakaiannya terbatas hanya sebagai cetakan awal. Bahan cetak harus tetap keakuratannya dan tetap stabil dalam dimensi sampai dituang ke dalam model stone. Keakuratan adalah aspek kemampuan mereproduksi nilai pengukuran yang benar, namun stabilitas dimensi ialah kemampuan mempertahankan keakuratan selama mungkin. (Mailoa, E, Dharmautama M, Rivani P. 2012) Menurut philips (1991), stabilitas dimensi bahan cetak alginat di pengaruhi oleh peristiwa sineresi dan imbibisi. Sineresis adalah suatu keadaan dimana bahan cetak alginat, saat berbentuk gel akan mengalami kehilangan air karena proses penguapan. Sedangkan imbibisi adalah suatu keadaan dimana bahan cetak alginat, saat berbentuk gel dan direndam air akan terjadi pengembangan pada bahan cetak (Febriani, M. 2012)

Dasar pemodifikasian alginat dengan beberapa bahan alami adalah kandungan polisakarida yang teradapat pada bahan alami tersebut. Kandungan polisakarida pada ubi kayu adalah 80,20\% dan pada sagu adalah 78,30\%. Kandungan polisakarida ubi kayu dan sagu terdiri dari amilosa dan amilopektin. Dimana kandungan amilosa dan amilopektin pada ubi kayu adalah $25 \%$ dan $75 \%$, sedangkan pada sagu 
adalah $27 \%$ dan $73 \%$. Perbandingan amilosa dan amilopektin akan mempengaruhi derajat gelatinisasi pati, semakin besar kandungan amilopektin maka gel yang di hasilkan dari proses gelatinisasi pati akan lebih basah, lengket dan cenderung sedikit menyerap air (Febriani, M. 2012; Ningsih, DS,. 2016). Proses pembentukan gel sangat di pengaruhi oleh perbandingan amilosa dan amilopektin. Senyawa amilosa dapat membuat pati menjadi mudah terikat dengan air ,sedangkan senyawa amilopektin dapat membuat pati membengkak atau terjadi proses pembesaran gel. Proses terbentuknya gel jika pati bercampur dengan air dan terdapatnya senyawa seperti amilosa dan amilopektin yang mampu menyerap serta mempertahankan air inilah yang dimanfaatkan dalam pencampurannya dengan alginate. (Roalika, DY. 2016)

Alginat menurut ANSI/ADA No.18/1992 dan ISO 1567/1978 sudah memenuhi persyaratan biokompabilitas sehingga tidak berbahaya bila digunakan di dalam mulut pasien. Begitupun dengan pati ubi kayu dan pati sagu yang memenuhi syarat FAO (Food Agricultural organization) sebagai bahan yang dapat dikonsumsi oleh manusia. (Febrian, M. 2012). Berkaitan dengan pernyataan di atas perlu dilakukan penelitian untuk melihat perbandingan stabilitas dimensi dari hasil cetakan alginat yang telah dimodifikasi antara alginat yang ditambahkan pati ubi kayu dan alginat yang di tambahkan pati sagu

\section{BAHAN DAN METODE}

Penelitian ini menggunakan metode True Eksperimental Laboratorium dengan rancangan cross sectional yang dilakukan di laboratorium terpadu Fakultas Kedokteran Gigi Universitas Muslim Indonesia. Sampel penelitian ini adalah hasil cetakan alginat yang terdiri dari 24 sampel yang dibagi menjadi dua kelompok yaitu satu kelompok alginat yang ditambahkan dengan pati ubi kayu dengan perbandingan 50:50 dan satu kelompok alginat yang ditambahkan dengan pati sagu dengan perbandingan 50:50, kemudian setiap kelompok dilakukan uji stabilitas dimensi. Masing - masing kelompok terdiri dari 1 perlakuan. Penelitian ini jumlah sampel minimal diestimasikan berdasarkan rumus Federer sebagai berikut :

Keterangan : $\quad t=$ jumlah perlakuan

$$
\mathrm{n}=\text { jumlah ulangan }
$$

Dalam rumus ini akan digunakan $t=3$ karena menggunakan 3 perlakuan, maka jumlah sampel (n) minimal tiap kelompok ditentukan sebagai berikut:

$$
\begin{aligned}
(\mathrm{t}-1)(\mathrm{n}-1) & \geq 15 \\
(3-1)(\mathrm{r}-1) & \geq 15 \\
\mathrm{r} & \geq 8
\end{aligned}
$$




$$
\mathrm{r} \times \mathrm{t}=8 \times 3=24 \text { sampel }
$$

Data penelitian kemudian dianalisis menggunakan Uji One Way Anova.

\section{HASIL}

TABEL 1 Stabilitas Bahan Cetak Alginat Murni

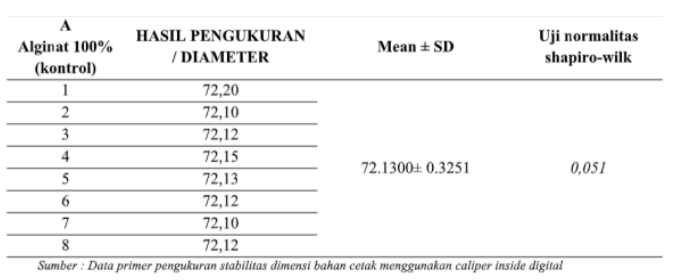

TABEL 2 Stabilitas Bahan Cetak Alginat Ditambah Pati Ubi Kayu Dengan Perbandingan

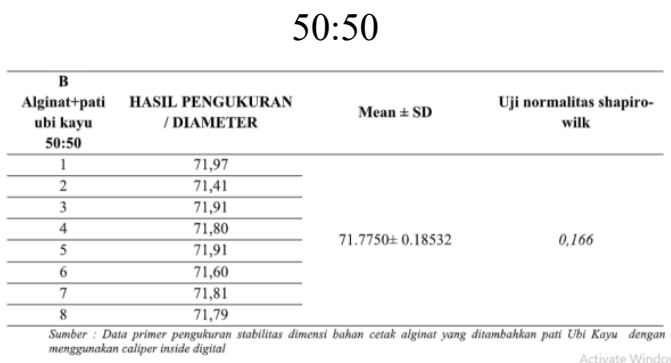

TABEL 3 Stabilitas Bahan Cetak Alginat Ditambah Pati Sagu Dengan Perbandingan 50:50

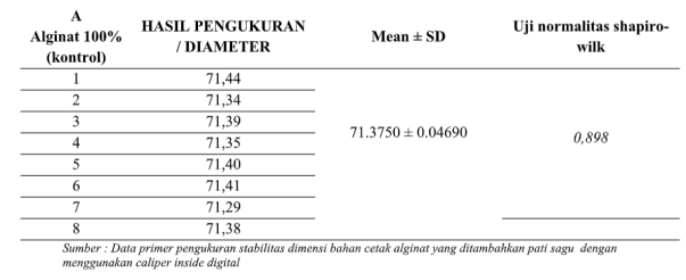

TABEL 4 uji parametrik one way anova

\begin{tabular}{|c|c|c|}
\hline Kelompok & Mean \pm SD & p-value (Sig.) \\
\hline Alginat murni & $72.1300 \pm 0.3251$ & \multirow{3}{*}{0,000} \\
\hline Alginat + pati ubi kayu & $71.7750 \pm 0.18532$ & \\
\hline Alginat + pati sagu & $71.3750 \pm 0.04690$ & \\
\hline
\end{tabular}

TABEL 5 Perbandingan penambahan pati ubi kayu dan pati sagu terhadap stabilitas dimensi hasil cetakan alginate

\begin{tabular}{lccc}
\multicolumn{1}{c}{ Kelompok } & $\begin{array}{c}\text { Perbedaan rata-rata } \\
(\text { Mean Differenc) } \\
(\mathrm{mm})\end{array}$ & p-value (Sig.) & p-value (Sig.) \\
$\begin{array}{llcc}\text { Alginat murni - (Alginat + pati ubi } \\
\text { kayu) }\end{array}$ & $0,35500^{*}$ & 0,000 & \\
$\begin{array}{l}\text { Alginat murni - (Alginat + pati } \\
\text { sagu) }\end{array}$ & $0,75500^{*}$ & 0,000 & 0,000 \\
$\begin{array}{l}\text { (Alginat + pati ubi kayu) - (Alginat } \\
\text { + pati sagu) }\end{array}$ & $0.40000^{*}$ & 0,000 & \\
\hline
\end{tabular}


Hal ini menunjukkan bahwa terdapat perbedaan yang signifikan pada nilai rata-rata dimensi dari alginat murni yang ditambahkan pati ubi kayu dengan alginat yang ditambahkan pati sagu.

\section{PEMBAHASAN}

Pada penelitian ini diketahui bahwa penambahan pati ubi kayu dan pati sagu dengan alginat perbandingan 50:50 mengalami perubahan yang signifikan dikarenakan takaran dari alginat murni dan alginat yang ditambahkan bahan alami memiliki perbandingan yang sama. Tabel 4 rata-rata diameter bahan cetak alginat murni sebesar 72,1300 untuk alginat yang ditambahkan pati ubi kayu sebesar 71,7750 dan untuk alginat yang ditambahkan pati sagu sebesar 71,3750. Dari hasil tersebut didapatkan bahwa nilai rata-rata kelompok perlakuan lebih kecil dari kelompok kontrol. Berdasarkan uji one way anova diperoleh $p$-value sebesar $0,000(\mathrm{p}<0,05)$ atau lebih kecil dari 0,05. Dengan demikian $\mathrm{H}_{0}$ ditolak dan Ha diterima artinya bahwa terdapat perbedaan yang signifikan terhadap penambahan pati ubi kayu dan pati sagu pada alginat murni.

Kandungan polisakarida pada ubi kayu adalah 80,20\% dan pada sagu adalah 78,30\%. Kandungan polisakarida ubi kayu dan sagu ini terdiri dari amilosa dan amilopektin. Kandungan amilosa dan amilopektin pada ubi kayu adalah $25 \%$ dan $75 \%$, sedangkan pada sagu adalah $27 \%$ dan $73 \%$. Amilopektin mempengaruhi proses gelatinisasi yang terjadi pada saat dicampur dengan air, karena molekul air di sekitar granula pati sagu akan memutuskan ikatan hidrogen dan masuk ke dalam granula pati sagu. Apabila kadar amilosa tinggi, maka pati akan bersifat kering, kurang lekat dan cenderung meresap air lebih banyak. Tingkat pengembangan dan penyerapan air tergantung pada kandungan amilosa. Makin tinggi kandungan amilosa, kemampuan pati untuk menyerap dan mengembang menjadi lebih besar karena amilosa mempunyai kemampuan membentuk ikatan hidrogen yang lebih besar daripada amilopektin. (Febriani, M. 2012; Ningsih, DS,. 2016)

Oleh karena pati ubi kayu dan sagu sama-sama memiliki kandungan amilopektin yang cukup tinggi , maka pati tersebut kurang menyerap air, sehingga hasil cetakan alginat pada kelompok perlakuan tabel 2 dan .3 lebih rendah rata-ratanya dibandingkan pada kelompok kontrol tabel 1 .

Tabel 5 menunjukkan dari kedua bahan alami tersebut didapatkan bahwa perbedaan rata-rata antara pati ubi kayu ditambah alginat dengan kelompok kontrol sebesar $0,35500^{*}$ sedangkan untuk pati sagu ditambah alginat dengan kelompok kontrol sebesar $0,75500^{*}$ dengan signifikansi perbedaan sebesar 0,000 . artinya terdapat perubahan yang signifikan pada pati sagu dan pati ubi kayu. Perbedaan antara alginat murni yang di bandingkan dengan pati ubi kayu lebih kecil nilainya dibandingkan antara alginat murni dengan pati sagu. Saat cetakan alginat terpapar udara pada suhu ruangan, maka akan terjadi penyusutan akibat sineresis. Imbery dkk (2010) mengatakan bahwa sineresis adalah hasil dari penyusunan kembali rantai silang polimer alginat untuk konfigurasi yang lebih stabil, sehingga terjadi 
pengeluaran air. Hal lain yang mempengaruhi stabilitas dimensi adalah distortion atau creep yang terjadi jika bahan cetak alginat tidak mengalami recovery elastic atau perubahan elastisitas saat bahan cetak alginat mengeras. Selama pengerasan, perubahan dimensi juga dapat terjadi akibat kontraksi yang berhubungan dengan ikatan silang di dalam atau diantara rantai polimer alginat.

Penelitian ini sejalan dengan penelitian yang dilakukan oleh Waruru FC (2016) Alginat dapat mengalami perubahan dimensi karena adanya proses sineresis dan imbibisi, dan juga menurut Ningsih DS (2016) tentang uji setting time pada modifikasi alginat dengan penambahan tepung jagung (Zea Mays) sebagai alternatif bahan cetak yang menyatakan bahwa tepung jagung mengandung amilosa dengan derajat gelatinisasi rendah sehingga proses penyerapan air pun rendah dan lambat.(Ningsih, DS, 2016)

Menurut Craig (2006), sesaat setelah terjadinya proses ikatan cross-link pada bahan cetak alginat akan membentuk gel network yang irreversible dan tidak akan terjadi perubahan bentuk dari gel menjadi sol. Bila tidak terjadi perubahan bentuk dari gel menjadi sol, dapat diartikan bahwa setelah terbentuk gel diharapkan tidak terjadi perubahan stabilitas dimensi pada bahan cetak alginat. Kemungkinan lain yang terjadi pada penelitian ini adanya proses evaporasi atau sineresis yang tidak terpengaruh dengan adanya penambahan pati ubi kayu dan sagu dalam bahan cetak alginat sehingga didapatkan nilai stabilitas dimensi yang berbeda.

Menurut Craig (2006), perubahan dimensi bahan cetak alginat berhubungan dengan kontraksi yang terjadi selama proses pengerasan atau setting time dari bahan cetak alginat, ini berhubungan dengan cross-linking yang terjadi didalam rantai polimer atau di antara rantai polimer alginat. Selain kontraksi, hal lain yang dapat mempengaruhi perubahan dimensi atau stabilitas dimensi adalah proses pengerutan atau shrinkage yang dapat menyebabkan hilangnya komponen air.

\section{KESIMPULAN DAN SARAN}

1. Nilai rerata stabilitas dimensi hasil cetakan hidrokoloid irreversible kelompok kontrol $(72,1300)$

2. Nilai rerata stabilitas dimensi hasil cetakan hidrokoloid irreversible kelompok alginat ditambah pati ubi kayu $(71,7750)$

3. Nilai rerata stabilitas dimensi hasil cetakan hidrokoloid irreversible kelompok alginat ditambah pati sagu $(71,3750)$

4. Dari kedua bahan alami tersebut didapatkan bahwa nilai signifikansi antara pati ubi kayu ditambah alginat dengan kelompok kontrol sebesar 0,000 sedangkan untuk pati sagu ditambah alginat dengan kelompok kontrol sebesar 0,000 . Berdasarkan uji one way anova diperoleh $p$-value sebesar $0,000(\mathrm{p}<0,05)$ atau lebih kecil dari 0,05 . 
Perlu dilakukan penelitian lebih lanjut dengan variasi perbandingan yang berbeda yaitu perbandingan yang lebih kecil. Diperlukan penelitian lebih lanjut tentang penambahan pati ubi kayu dan pati sagu pada alginat apakah konsentrasi tersebut menjadi akselelator atau retarder sehingga bahan cetak tidak terlalu berubah komposisinya.

\section{DAFTAR PUSTAKA}

1. Febriani M. 2012. Pengaruh penambahan pati ubi kayu pada bahan cetak alginate terhadap stabilitas dimensi. IDJ. 1(1): 2,4.

2. Ningsih DS. 2016. Uji setting time pada modifikasi alginate dengan penambahan tepung jagung (zea mays) sebagai alternative bahan cetak. Journal of Syiah Kuala Dentistry Society. 1(1): 59-60.

3. Mailoa E, Dharmautama M, Rovani P. 2012. Pengaruh teknik pencampuran bahan cetak alginate terhadap stabilitas dimensi linier model stone dari hasil cetakan. Bagian Ilmu Teknologi Materila Fakultas Kedokteran Gigi Universitas Hasanuddin. IDJ.; 11(3): 143.

4. Roalika DY. 2016 Pengaruh penambahan pati ubi kayu (Mannihot Utilisima) dalam berbagai konsentrasi terhadap stabilitas dimensi bahan cetak alginate. Pharmacon. p. 151.

5. Anusavice KJ. Philips: Buku ajar ilmu bahan kedokteran gigi. Ed 12. p.171.

6. Mutia T. 2011. Membran alginate sebagai pembalut luka primer dan media penyampaian obat topikals untuk luka yang terinfeksi. Jurnal Riset Industri. 5(2): 166.

7. Saba DA. 2011. Effect of composition of alginate impression material on "recovery from deformation". Journal of American Science. 7(9): 443.

8. Winursito I. 2013 Biodegradabilitas polikarbosilat dari asam alginate dan tapioca. Jurnal Litbang Industri. 3(1): 40.

9. McCabe JF, Angus WG. 2015. Applied dental materials. Ed 9. Blackwell; p.159-60.

10. Febriani M. 2011. Alginat impression vs alginate impression plus cassava starch: analisis gambaran mikroskopik stomatognatic. Jurnal Kedokteran Gigi Universitas Jember. 8(2): $68-70$.

11. Fraunhofer JA. 2013. Dental materials at a glance. Ed 2. USA: Wiley Blackwell; p.31

12. Koapaha T. 2011. Penggunaan pati sagu modifikasi fosfat terhadap sifat organoleptik sosis ikan patin (Pangasuius Hypopthalmus). Eugenia. 17(1): 81.

13. Ulung G. 2011 Extremely Beautiful Maluku. Jakarta: Gramedia. p.198. 